\title{
Efficacy of Hemospray in non-variceal upper gastrointestinal bleeding: a systematic review with meta-analysis
}

\author{
Muhammad Aziz ${ }^{\mathrm{a} *}$, Simcha Weissman ${ }^{\mathrm{b} *}$, Tej I. Mehtac, Shafae Hassan ${ }^{\mathrm{d}}$, Zubair Khana, Rawish Fatimaa, \\ Yuriy Tsirline, Ammar Hassanf, Michael Sciarraf, Ali Nawras ${ }^{d}$, Amit Rastogig \\ University of Toledo Medical Center, Toledo, Ohio; Hackensack University-Palisades Medical Center, North Bergen, \\ New Jersey; University of South Dakota Sanford School of Medicine, Sioux Falls, South Dakota; Maimonides Medical \\ Center, Brooklyn, New York; University of Kansas Medical Center, Kansas City, Kansas, USA
}

Abstract

Background Recently, amongst other hemostatic modalities, Hemospray (TC-325) has emerged as an effective method for managing patients with non-variceal upper gastrointestinal bleeding (GIB). We conducted this systematic review and meta-analysis to assess the efficacy of Hemospray in patients with non-variceal upper GIB.

Methods Our primary outcomes were clinical and technical success; secondary outcomes were aggregate rebleeding, early rebleeding, delayed rebleeding, refractory bleeding, mortality, and treatment failure. A meta-analysis of proportions was conducted for all reported primary and secondary outcomes. A relative risk meta-analysis was conducted for studies reporting direct comparisons between Hemospray and other hemostatic measures.

Results A total of 20 studies with 1280 patients were included in the final analysis. Technical success of Hemospray was seen in $97 \%$ of cases (95\% confidence interval [CI] 94-98\%, $I^{2}=52.89 \%$ ) and a significant trend towards increasing technical success was seen during publication years 2011-2019. Clinical success of Hemospray was seen in $91 \%$ of cases (95\%CI $\left.88-94 \%, I^{2}=47.72 \%\right)$, compared to $87 \%\left(95 \%\right.$ CI $\left.75-94 \%, I^{2}=0.00 \%\right)$ for other hemostatic measures. The secondary outcomes of aggregate rebleeding, early rebleeding, delayed rebleeding, refractory rebleeding, mortality and treatment failure following the use of Hemospray were seen in $27 \%, 20 \%, 9 \%, 8 \%, 8 \%$, and $31 \%$ of cases, respectively.

Conclusion Hemospray is safe, effective and non-inferior to traditional hemostatic measures for the management of non-variceal upper GIB, and can thus be used as an alternative option.

Keywords Non variceal bleeding, upper gastrointestinal bleeding, Hemospray, TC-325, hemostasis Ann Gastroenterol 2020; 33 (1): 1-19

Department of a Internal Medicine, University of Toledo Medical Center, Toledo, Ohio (Muhammad Aziz, Zubair Khan, Rawish Fatima); ${ }^{\text {b} M e d i c i n e, ~ H a c k e n s a c k ~ U n i v e r s i t y-P a l i s a d e s ~ M e d i c a l ~ C e n t e r, ~ N o r t h ~}$ Bergen, New Jersey (Simcha Weissman); 'Medicine, University of South Dakota Sanford school of Medicine, Sioux Falls, South Dakota (Tej I. Mehta); ${ }^{\mathrm{d}}$ Gastroenterology, University of Toledo Medical Center, Toledo, Ohio (Shafae Hassan, Ali Nawras); 'Gastroenterology, Maimonides Medical Center, Brooklyn, New York (Yuriy Tsirlin); ${ }^{\mathrm{f}}$ Division of Gastroenterology and Hepatology, Hackensack University-Palisades Medical Center, North Bergen, New Jersey (Ammar Hassan, Michael Sciarra); ${ }^{\mathrm{D}}$ Department of Gastroenterology and Hepatology, University of Kansas Medical Center, Kansas City, Kansas (Amit Rastogi), USA

Conflict of Interest: Dr. Rastogi is a consultant for Cook Medical, the developer of Hemospray

Correspondence to: Muhammad Aziz, MD, University of Toledo Medical Center, 3000 Arlington Avenue, Toledo, Ohio, 43614 USA, e-mail:marajani@hotmail.com

Received 25 August 2019; accepted 20 November 2019; published online 20 January 2020

DOI: https://doi.org/10.20524/aog.2020.0448

๑ 2020 Hellenic Society of Gastroenterology

\section{Introduction}

With approximately 1 case per 1000 persons and 20,000 deaths reported annually, gastrointestinal bleeding (GIB) is amongst the leading causes of morbidity and mortality in the United States [1]. Several endoscopic methods to control GIB, such as injectable, thermal and mechanical therapies are routinely used with success. Recently novel hemostatic agents have shown promising results while requiring less technical expertise for effective administration [2]. These hemostatic powders appear to be a simple, safe and effective method for achieving endoscopic hemostasis [2]. One such agent is TC-325 (Hemospray, Cook Medical, WinstonSalem, NC, USA), a sprayable powder studied in animal and human models for the termination of acute bleeding. As a highly absorptive, inert mineral powder, Hemospray is able to coagulate an active gastrointestinal bleed for up to 48-72 h and its mode of application allows expeditious coverage of large surface areas [3]. The principle hemostatic mechanism of Hemospray is a mechanical tamponade over the bleeding 
arterial wall. A secondary mechanism of action is via an increase in clotting factor concentration, with the downstream effect of robust coagulation cascade activation and immediate clotting [4].

The perceived ease of use, along with its ability to cover a large surface area, makes Hemospray an attractive modality for the treatment of GIB [5]. In addition, it carries a low risk of systemic toxicity, as most of the powder is eliminated in stool and not absorbed via gastrointestinal mucosa. Its effectiveness in achieving hemostasis has been demonstrated in bleeding from numerous etiologies, including peptic ulcers, esophageal varices, therapeutic endoscopic procedures, and those of the lower gastrointestinal tract [3-7]. Additionally, Hemospray has been used successfully in cancer-related bleeding and as a bridge to other, definitive hemostatic modalities [6,7].

Although Hemospray has been approved by the Food and Drug administration for non-variceal upper GIB, there is a lack of large prospective randomized controlled studies assessing its safety and efficacy compared to conventional modalities. Previous review articles have attempted to gather preliminary results on the use of Hemospray, but these were limited by insufficient data collection and statistical power. We conducted a systematic review and meta-analysis to assess the efficacy of Hemospray for the treatment of non-variceal upper GIB.

\section{Materials and methods}

\section{Search strategy}

A comprehensive search analysis was performed using the electronic databases MEDLINE/PubMed, Cochrane and Google Scholar through April 30, 2019, to identify all pertinent articles. MeSH terms "Hemospray", "TC-325", "gastrointestinal hemorrhage", and "bleeding" were used in different combinations to generate an up-to-date list of articles. Two individual reviewers (MA and SW) performed the search independently and shortlisted the articles for final review. Any disagreement was resolved through mutual discussion and screening by a third reviewer (TM). Articles were initially screened by titles and abstracts. Full text was obtained for final shortlisted studies. We used the PRISMA guidelines to select the final articles, as shown in Supplementary Fig. 1. The search strategy for PubMed is highlighted in Supplementary Table 1.

\section{Inclusion and exclusion criteria}

We limited our search strategy to include randomized controlled trials (RCTs), dual-arm cohort studies comparing Hemospray to other hemostatic methods for upper GIB, and single-arm cohort studies reporting data on Hemosprayrelated hemostasis and outcomes. We excluded review articles, case reports, studies with 10 or fewer patients, and letters to the Editor. The search strategy was not restricted by language or date. We excluded abstracts from our final analysis.

\section{Study definitions}

"Technical success" was defined as successful use of Hemospray powder during endoscopy without technical difficulties (i.e., blockage through the application catheter, failure of trigger mechanism, breakage or malfunction of catheter or cartridge). "Clinical success" was defined as achieving hemostasis immediately following the application of either hemostatic modality, i.e., Hemospray or conventional therapies. "Early rebleeding" was defined as failure of hemostasis resulting in bleeding at the target site within $72 \mathrm{~h}$ of applying the hemostatic modality. "Delayed rebleeding" was defined as bleeding at the target site $72 \mathrm{~h}$ or more after the application of the hemostatic modality. "Aggregate rebleeding" was defined as a combination of the "early rebleeding" and "delayed rebleeding" events. "Refractory bleeding" was defined as continued bleeding despite the use of the hemostatic modality. "Treatment failure" was defined as a combination of the "refractory bleeding" and "aggregate rebleeding" events. The "intervention group" included the patients in whom Hemospray was utilized. The "control group" comprised the patients in whom hemostasis was applied using methods other than Hemospray.

\section{Primary and secondary outcomes}

Primary outcomes included intraprocedural technical and clinical success in the control and intervention groups. Secondary outcomes included refractory bleeding rate, rebleeding rate (immediate, delayed and aggregate), treatment failure rate, and mortality due to bleeding.

\section{Data collection}

Demographic data (age, sex), number of study participants (delineated by control and intervention groups when available), hemostatic agent used for control groups (when available), follow-up time, median Rockall score, median Blatchford score, hemoglobin at time of treatment, use of antithrombotic agents, as well as bleeding source and etiology were extracted from each study. The data collection was performed by 2 individual reviewers (MA and SW) and any discrepancy was resolved by a third reviewer (TM).

\section{Data synthesis and statistical analysis}

Data were extracted and collected in Microsoft Excel (Microsoft, Redmond, Washington, United States) and tabulated according to the categories of variables mentioned above. R package "metafor" (version 2.1-0) was used for metaanalysis, tests for heterogeneity and analysis of publication bias. Weighted random effects models were used to calculate proportional estimates of primary and secondary outcomes for studies reporting data on patients with Hemospray 
Table 1 Study details and baseline demographics of the patients in the included studies

\begin{tabular}{|c|c|c|c|c|c|c|c|c|}
\hline Author & Year & Journal & $\begin{array}{l}\text { Type of } \\
\text { study }\end{array}$ & $\begin{array}{l}\text { Length of Follow } \\
\text { up, n days }\end{array}$ & $\begin{array}{l}\text { Control } \\
\text { group, } \mathrm{n}\end{array}$ & $\begin{array}{l}\text { Intervention } \\
\text { group, } \mathrm{n}\end{array}$ & Age, $\mathrm{n}$ & $\begin{array}{c}\text { Male sex, } \\
\text { n (\%) }\end{array}$ \\
\hline $\begin{array}{l}\text { Arena } \\
\text { et al [6] }\end{array}$ & 2017 & $\begin{array}{l}\text { Digestive and } \\
\text { Liver Disease }\end{array}$ & $\begin{array}{l}\text { Retrospective } \\
\text { Cohort }\end{array}$ & 180 & N/A & 15 & 74 & $8(53)$ \\
\hline $\begin{array}{l}\text { Baracat } \\
\text { et al [10] }\end{array}$ & 2019 & $\begin{array}{l}\text { Surgical } \\
\text { Endoscopy }\end{array}$ & RCT & 7 & 20 & 19 & 56.8 & $26(67)$ \\
\hline $\begin{array}{l}\text { Cahyadi } \\
\text { et al [12] }\end{array}$ & 2017 & $\begin{array}{l}\text { Endoscopy } \\
\text { International } \\
\text { Open }\end{array}$ & $\begin{array}{l}\text { Retrospective } \\
\text { Cohort }\end{array}$ & 7 & N/A & 52 & 69 & $31(60)$ \\
\hline $\begin{array}{l}\text { Giles } \\
\text { et al [13] }\end{array}$ & 2016 & $\begin{array}{l}\text { The New Zealand } \\
\text { Medical Journal }\end{array}$ & $\begin{array}{l}\text { Retrospective } \\
\text { Cohort }\end{array}$ & 480 & N/A & 36 & 68.6 & $25(69)$ \\
\hline $\begin{array}{l}\text { Haddara } \\
\text { et al [14] }\end{array}$ & 2016 & Endoscopy & $\begin{array}{l}\text { Retrospective } \\
\text { Cohort }\end{array}$ & 30 & N/A & 202 & 68.9 & $140(69.3)$ \\
\hline $\begin{array}{l}\text { Hagel } \\
\text { et al [15] }\end{array}$ & 2017 & $\begin{array}{l}\text { Gastroenterology } \\
\text { Research and } \\
\text { Practice }\end{array}$ & $\begin{array}{l}\text { Prospective } \\
\text { Cohort }\end{array}$ & 480 & N/A & 25 & 72 & $18(72)$ \\
\hline $\begin{array}{l}\text { Holster } \\
\text { et al [16] }\end{array}$ & 2012 & Endoscopy & $\begin{array}{l}\text { Prospective } \\
\text { Cohort }\end{array}$ & 30 & N/A & 15 & 69.5 & $12(80)$ \\
\hline $\begin{array}{l}\text { Kwek } \\
\text { et al [11] }\end{array}$ & 2017 & $\begin{array}{l}\text { Journal of } \\
\text { Digestive } \\
\text { Diseases }\end{array}$ & RCT & 30 & 10 & 10 & 70 & $16(80)$ \\
\hline $\begin{array}{l}\text { Pittayanon } \\
\text { et al [17] }\end{array}$ & 2016 & $\begin{array}{l}\text { Endoscopy } \\
\text { International } \\
\text { Open }\end{array}$ & $\begin{array}{l}\text { Prospective } \\
\text { Cohort }\end{array}$ & 30 & 10 & 10 & 61.8 & $16(80)$ \\
\hline $\begin{array}{l}\text { Pittayanon } \\
\text { et al [18] }\end{array}$ & 2018 & $\begin{array}{l}\text { Gastrointestinal } \\
\text { Endoscopy }\end{array}$ & $\begin{array}{l}\text { Retrospective } \\
\text { Cohort }\end{array}$ & 30 & N/A & 50 & NR & NR \\
\hline $\begin{array}{l}\text { Sinha } \\
\text { et al [19] }\end{array}$ & 2016 & $\begin{array}{l}\text { Gastrointestinal } \\
\text { Endoscopy }\end{array}$ & $\begin{array}{l}\text { Retrospective } \\
\text { Cohort }\end{array}$ & 30 & 20 & 20 & 73 & $10(50)$ \\
\hline $\begin{array}{l}\text { Sulz } \\
\text { et al [20] }\end{array}$ & 2014 & Endoscopy & $\begin{array}{l}\text { Prospective } \\
\text { Cohort }\end{array}$ & 7 & N/A & 15 & 67 & $12(80)$ \\
\hline $\begin{array}{l}\text { Sung } \\
\text { et al [21] }\end{array}$ & 2011 & Endoscopy & $\begin{array}{l}\text { Prospective } \\
\text { Cohort }\end{array}$ & 30 & N/A & 20 & 60.2 & $18(90)$ \\
\hline $\begin{array}{l}\text { Vitali } \\
\text { et al [22] }\end{array}$ & 2019 & $\begin{array}{l}\text { World Journal of } \\
\text { Gastroenterology }\end{array}$ & $\begin{array}{l}\text { Prospective } \\
\text { Cohort }\end{array}$ & 30 & N/A & 91 & NR & NR \\
\hline $\begin{array}{l}\text { Yau } \\
\text { et al [23] }\end{array}$ & 2013 & $\begin{array}{l}\text { Canadian } \\
\text { Journal of } \\
\text { Gastroenterology } \\
\text { and Hepatology }\end{array}$ & $\begin{array}{l}\text { Retrospective } \\
\text { Cohort }\end{array}$ & NR & N/A & 19 & 67.6 & $14(74)$ \\
\hline $\begin{array}{l}\text { Smith } \\
\text { et al [24] }\end{array}$ & 2014 & $\begin{array}{l}\text { Journal of } \\
\text { Clinical } \\
\text { Gastroenterology }\end{array}$ & $\begin{array}{l}\text { Retrospective } \\
\text { Cohort }\end{array}$ & NR & N/A & 63 & 69 & $44(70)$ \\
\hline $\begin{array}{l}\text { Masci } \\
\text { et al [25] }\end{array}$ & 2014 & $\begin{array}{l}\text { Scandinavian } \\
\text { Journal of } \\
\text { Gastroenterology }\end{array}$ & $\begin{array}{l}\text { Prospective } \\
\text { Cohort }\end{array}$ & 7 & N/A & 13 & 70.3 & $9(69)$ \\
\hline $\begin{array}{l}\text { Leblanc } \\
\text { et al [26] }\end{array}$ & 2013 & $\begin{array}{l}\text { Gastrointestinal } \\
\text { Endoscopy }\end{array}$ & $\begin{array}{l}\text { Prospective } \\
\text { Cohort }\end{array}$ & 30 & N/A & 12 & 62.2 & $9(75)$ \\
\hline $\begin{array}{l}\text { Alzoubaidi } \\
\text { et al [27] }\end{array}$ & 2019 & $\begin{array}{l}\text { Digestive } \\
\text { Endoscopy }\end{array}$ & $\begin{array}{l}\text { Prospective } \\
\text { Cohort }\end{array}$ & 30 & N/A & 314 & 71.0 & $231(74)$ \\
\hline $\begin{array}{l}\text { Santiago } \\
\text { et al [28] }\end{array}$ & 2019 & $\begin{array}{l}\text { Gastrointestinal } \\
\text { Endoscopy }\end{array}$ & $\begin{array}{l}\text { Retrospective } \\
\text { Cohort }\end{array}$ & 30 & N/A & 219 & N/A & N/A \\
\hline
\end{tabular}

$N / A$, not applicable; $N R$, not reported; $n$, no. of patients; $R C T$, randomized controlled trial

application using the DerSimonian-Laird method. For studies reporting data for control and intervention groups, weighted random-effects models were used to calculate log-transformed risk ratios. Since the studies involved 


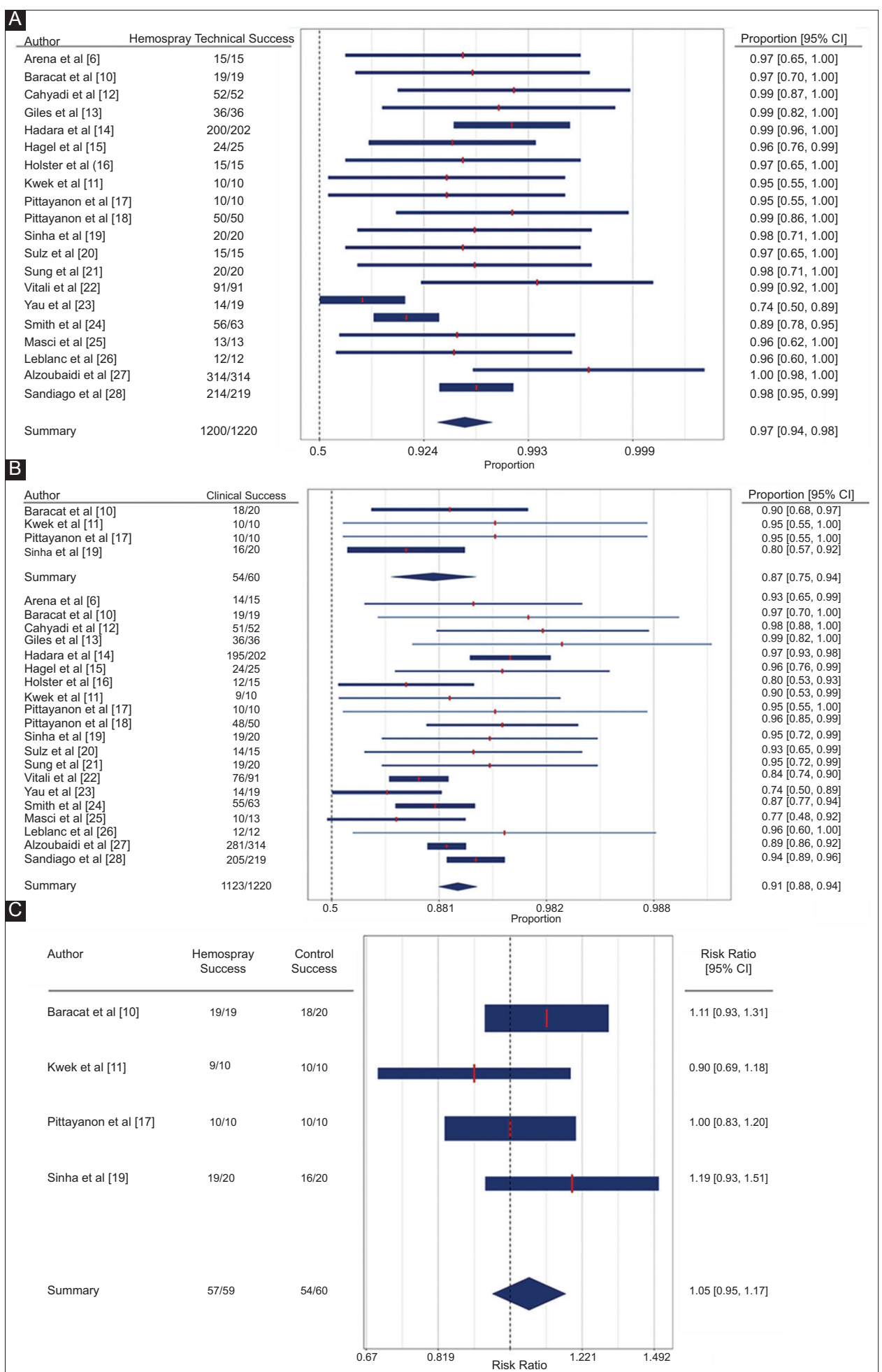

Figure 1 Forest plot with proportional analysis depicting (A) technical success (B) clinical success (C) risk ratio for clinical success

heterogeneous patient treatment decisions, a random-effects model was considered superior to a fixed-effects model for calculating sample effects. In addition, since the selected studies spanned numerous years and covered several different populations in various geographical locations, the random- effects model was considered more appropriate than the fixed-effects model. The $I^{2}$ statistic was used for identifying heterogeneity: $I^{2}$ values of $0 \%, 25 \%, 50 \%$ and $75 \%$ were interpreted as absent, low, moderate and high heterogeneity, respectively [8]. Meta-regression analysis was conducted for 
outcomes with $I^{2}$ greater than $50 \%$ to elucidate sources of heterogeneity. The beta of the intercept and the moderating factor are reported as log proportions, in addition to the $\mathrm{P}$-value of the Wald test for moderators (QMp), the percentage of heterogeneity accounted for $\left(\mathrm{R}^{2}\right)$ and the remaining heterogeneity $\left(I^{2}\right)$. Differences in demographic variables were assessed using a 2 -sample $t$-test. A P-value of $<0.05$ was considered statistically significant when comparing risk ratios or proportions between 2 groups. Confidence intervals are displayed with an alpha of 0.05 .

\section{Bias assessment}

The risk of bias for RCTs was evaluated using the methodology outlined in the Cochrane Handbook for Systematic Reviews of Interventions [8]. Bias in non-RCTs was evaluated based on the Newcastle-Ottawa scale, with each study scored on a total of 8 points ( 4 selection, 1 comparability, and 3 outcome) [9].

\section{Results}

\section{Study details and demographics}

A total of 149 records were retrieved based on our search strategy (Supplementary Fig. 1). After a comprehensive review of the published literature, a total of 20 studies met the inclusion and exclusion criteria for this meta-analysis [6,10-28]. All included studies were published between 2011 and 2019.

Study details and baseline demographics are summarized in Table 1. A total of 2 RCTs and 18 observational studies (retrospective and prospective) were part of the final analysis (Table 1). The risk of overall bias in the included RCTs was low to moderate (Supplementary Table 2). The included cohort studies had a score of $\geq 5$ on the Newcastle-Ottawa scale (Supplementary Table 3). Publication bias was difficult to assess, as only 4 studies included a control arm $[10,11,18,19]$. These studies are represented in the relative risk (RR) meta-analysis. The total number of patients across all studies was 1280 .

One hundred nineteen patients were included in the RR meta-analysis (4 studies, 60 patients in the control group and 59 in the intervention group). The mean age was 65.2 years and 66.0 years for the control and intervention groups, respectively. The 2 groups also showed similar sex distributions $(63.3 \%$ vs. $69.5 \%$ males for the control and intervention groups, respectively). All studies with control groups reported the hemostatic agent(s) used, which included: endoscopic hemoclip application, thermal treatment, pharmacotherapy (fluids, blood, octreotide, adrenaline injection), and/or adrenaline injection.

A total of 1280 patients (1161 patients from single-arm and 119 from dual-arm studies) were included in the proportional meta-analysis. Of these, 1220 patients received Hemospray and 60 received other hemostatic agents. There was no significant age difference between Hemospray recipients and non-Hemospray recipients (67.7 and 63.0 years. respectively, $\mathrm{P}=0.43$ ). There was no significant difference regarding the sex distribution of Hemospray and non-Hemospray recipients (57\% and 68\% males, respectively, $\mathrm{P}=0.08$ ). Among Hemospray recipients, the median Rockall score was 6.6, the median Blatchford score was 10.5 and the median hemoglobin at time of treatment was $8.0 \mathrm{~g} / \mathrm{dL}$. In the control group, the median Rockall score was 7.1, the median Blatchford score was 10.5 and the median hemoglobin at time of treatment was $8.0 \mathrm{~g} / \mathrm{dL}$. No significant differences were found.

\section{Proportional meta-analysis}

\section{Primary outcomes}

Primary and secondary outcomes are summarized in Supplementary Tables 4 and 5. All studies reported the technical success of Hemospray powder (Fig. 1 A,B,C), which was seen in $97 \%$ of patients ( $95 \%$ confidence interval [CI] 94-98\%, $\left.I^{2}=52.89 \%\right)$. A thick forest plot demonstrating these data is shown in Fig. 1A. Year of publication had a significant moderating effect on technical success $\left(\right.$ beta $_{0}=1.51$, betan=study year $-2011=0.35, \mathrm{QMp}<0.01, \mathrm{R}^{2}=97.38, I^{2}=11 \%$ ) (Supplementary Fig. 2). Clinical success for Hemospray was seen in $91 \%$ of patients ( $95 \%$ CI $88-94 \%, I^{2}=47.72 \%$ ), compared to $87 \%$ of patients in the control group (95\% CI $75-94 \%$, $\left.I^{2}=0.00 \%\right)$. A thick forest plot demonstrating these data is seen in Fig. 1B.

\section{Secondary outcomes}

Early rebleeding following the use of Hemospray was seen in $20 \%$ of patients ( $95 \%$ CI $14-29 \%, I^{2}=56.73 \%$ ), compared to $12 \%$ in the control group (95\%CI $1-68 \%, I^{2}=69.27 \%$ ) (Supplementary Fig. 3 A,B). Median Rockall score had a significant moderating effect on early rebleeding in the intervention group (beta $_{0}=-5.27$, beta ${ }_{\mathrm{n}=\text { Rockall }}=0.71, \mathrm{QMp}<0.01$, $\left.\mathrm{R}^{2}=100 \%, I^{2}=0 \%\right)$. However, only 3 studies reported Rockall score and early rebleeding. No significant moderators were found for the control group. Delayed rebleeding following the use of Hemospray was seen in $9 \%$ of patients $(95 \%$ CI $6-12 \%$, $I^{2}=0.00 \%$ ), compared to $13 \%$ in the control group (95\%CI 4-31\%, $I^{2}=0.00 \%, 2$ studies) (Supplementary Fig. 4 A,B). Refractory rebleeding following the use of Hemospray was seen in $8 \%$ of patients ( $95 \% \mathrm{CI} 6-11 \%, I^{2}=41.16 \%$ ), compared to $13 \%$ in the control group (95\%CI 6-25\%, $I^{2}=0.00 \%, 4$ studies) (Supplementary Fig. 5 A,B). Aggregate rebleeding rate following the use of Hemospray was seen in $24 \%$ of patients (95\%CI $18-31 \%, I^{2}=77.57 \%$ ), compared to $19 \%$ in the control group (95\%CI $11-31 \%, I^{2}=0.00 \%$, 4 studies) (Fig. 2 A,B). No significant moderators were identified for the intervention group.

Treatment failure following the use of Hemospray was seen in $31 \%$ of patients $\left(95 \% \mathrm{CI} 26-37 \%, I^{2}=66.05 \%\right.$ ), while treatment failure following the use of other hemostatic measures was 
Table 2 Primary and secondary outcomes for patients in the Hemospray group in the included studies

\begin{tabular}{|c|c|c|c|c|c|c|c|c|}
\hline Author & $\begin{array}{c}\text { Technical } \\
\text { Success, } \\
\text { n (\%) }\end{array}$ & $\begin{array}{c}\text { Clinical } \\
\text { Success, } \\
\text { n (\%) }\end{array}$ & $\begin{array}{c}\text { Refractory } \\
\text { bleeding, } \\
\text { n (\%) }\end{array}$ & $\begin{array}{c}\text { Early } \\
\text { rebleeding, } \\
\mathrm{n}(\%)\end{array}$ & $\begin{array}{l}\text { Delayed } \\
\text { rebleeding, } \\
\mathrm{n}(\%)\end{array}$ & $\begin{array}{c}\text { Aggregate } \\
\text { Rebleeding, } \\
\text { n (\%) }\end{array}$ & $\begin{array}{l}\text { Adverse } \\
\text { events, } \\
\text { n (\%) }\end{array}$ & $\begin{array}{c}\text { Mortality, } \\
\text { n (\%) }\end{array}$ \\
\hline $\begin{array}{l}\text { Arena } \\
\text { et al [6] }\end{array}$ & $15(100)$ & $14(93)$ & $1(7)$ & $2(13)$ & $1(7)$ & $3(20)$ & $0(0)$ & $3(20)$ \\
\hline $\begin{array}{l}\text { Baracat } \\
\text { et al [10] }\end{array}$ & $19(100)$ & $19(100)$ & $0(0)$ & $5(26)$ & $3(16)$ & $8(42)$ & $0(0)$ & $4(21.1)$ \\
\hline $\begin{array}{l}\text { Cahyadi } \\
\text { et al [12] }\end{array}$ & $52(100)$ & $51(98)$ & $1(2)$ & $22(43)$ & $3(6)$ & $25(49)$ & $0(0)$ & $2(4)$ \\
\hline $\begin{array}{l}\text { Giles } \\
\text { et al [13] }\end{array}$ & $36(100)$ & $36(100)$ & $0(0)$ & NR & NR & $4(11)$ & $0(0)$ & $5(14)$ \\
\hline $\begin{array}{l}\text { Haddara } \\
\text { et al [14] }\end{array}$ & $200(99.0)$ & $195(97)$ & $7(4)$ & NR & NR & $62(31)$ & $0(0)$ & $7(4)$ \\
\hline $\begin{array}{l}\text { Hagel } \\
\text { et al [15] }\end{array}$ & $24(96)$ & $24(96)$ & $1(4)$ & NR & NR & $11(44)$ & $1(4)$ & $1(4)$ \\
\hline $\begin{array}{l}\text { Holster } \\
\text { et al [16] }\end{array}$ & $15(100)$ & $12(80)$ & $3(20)$ & $4(27)$ & $1(7)$ & $5(33)$ & $0(0)$ & $0(0)$ \\
\hline $\begin{array}{l}\text { Kwek } \\
\text { et al [11] }\end{array}$ & $10(100)$ & $9(90)$ & $1(10)$ & NR & NR & $3(30)$ & $0(0)$ & NR \\
\hline $\begin{array}{l}\text { Pittayanon } \\
\text { et al [17] }\end{array}$ & $10(100)$ & $10(100)$ & $0(0)$ & $0(0)$ & $1(10)$ & $1(10)$ & $0(0)$ & NR \\
\hline $\begin{array}{l}\text { Pittayanon } \\
\text { et al [18] }\end{array}$ & $50(100)$ & $48(96)$ & $2(4)$ & $8(16)$ & $7(14)$ & $15(30)$ & $1(2)$ & NR \\
\hline $\begin{array}{l}\text { Sinha } \\
\text { et al [19] }\end{array}$ & $20(100)$ & $19(95)$ & $1(5)$ & NR & NR & $3(15)$ & $0(0)$ & $1(5)$ \\
\hline Sulz et al [20] & $15(100)$ & $14(93)$ & $1(7)$ & $2(13)$ & NR & $2(13)$ & $0(0)$ & $0(0)$ \\
\hline $\begin{array}{l}\text { Sung } \\
\text { et al [21] }\end{array}$ & $20(100)$ & $19(95)$ & $1(5)$ & $3(15)$ & NR & NR & $0(0)$ & $0(0)$ \\
\hline $\begin{array}{l}\text { Vitali } \\
\text { et al [22] }\end{array}$ & $91(100)$ & $76(84)$ & $1(20)$ & NR & NR & $19(21)$ & $2(2)$ & NR \\
\hline Yau et al [23] & $14(93)$ & $14(93)$ & $15(17)$ & NR & NR & $7(37)$ & $2(11)$ & $1(5)$ \\
\hline $\begin{array}{l}\text { Smith } \\
\text { et al [24] }\end{array}$ & $56(89)$ & $55(87)$ & $1(7)$ & NR & NR & $9(14)$ & $0(0)$ & $0(0)$ \\
\hline $\begin{array}{l}\text { Masci } \\
\text { et al [25] }\end{array}$ & $13(100)$ & $10(77)$ & $8(13)$ & $2(15)$ & NR & $2(15)$ & $0(0)$ & $0(0)$ \\
\hline $\begin{array}{l}\text { Leblanc } \\
\text { et al [26] }\end{array}$ & $12(100)$ & $12(100)$ & $3(23)$ & NR & NR & NR & $0(0)$ & NR \\
\hline $\begin{array}{l}\text { Alzoubaidi } \\
\text { et al [27] }\end{array}$ & $314(100)$ & $281(89)$ & $33(11)$ & NR & NR & $29(9)$ & $0(0)$ & NR \\
\hline $\begin{array}{l}\text { Santiago } \\
\text { et al [28] }\end{array}$ & $214(98)$ & $205(94)$ & $14(6)$ & $35(16)$ & $15(7)$ & $50(23)$ & $3(1)$ & $19(9)$ \\
\hline
\end{tabular}

N/A, not applicable; NR, not reported; $n$, no. of patients

seen in $30 \%\left(95 \%\right.$ CI $\left.19-43 \%, I^{2}=0.00 \%\right)$ (Supplementary Fig. 6 A,B). No significant moderators were identified for the intervention group. Mortality due to bleeding following the use of Hemospray was $8 \%$ (95\%CI 5-13\%, $I^{2}=32.54 \%$ ), while mortality due to bleeding following the use of other hemostatic measures was $21 \%$ (95\%CI $\left.11-34 \%, I^{2}=0.00 \%\right)$ (Supplementary Fig. 7A,B).

A total of 9 patients $(0.7 \%)$ experienced total 12 adverse events following the use of Hemospray. Of these, 8 gastrointestinal perforation, 1 splenic infarction, 1 cardiorespiratory arrest, 1 pulmonary thromboembolism, and 1 abdominal pain (Table 2).

\section{RR meta-analysis}

\section{Primary outcomes}

Four studies compared the clinical success of Hemospray to that of other hemostatic techniques and found no significant 


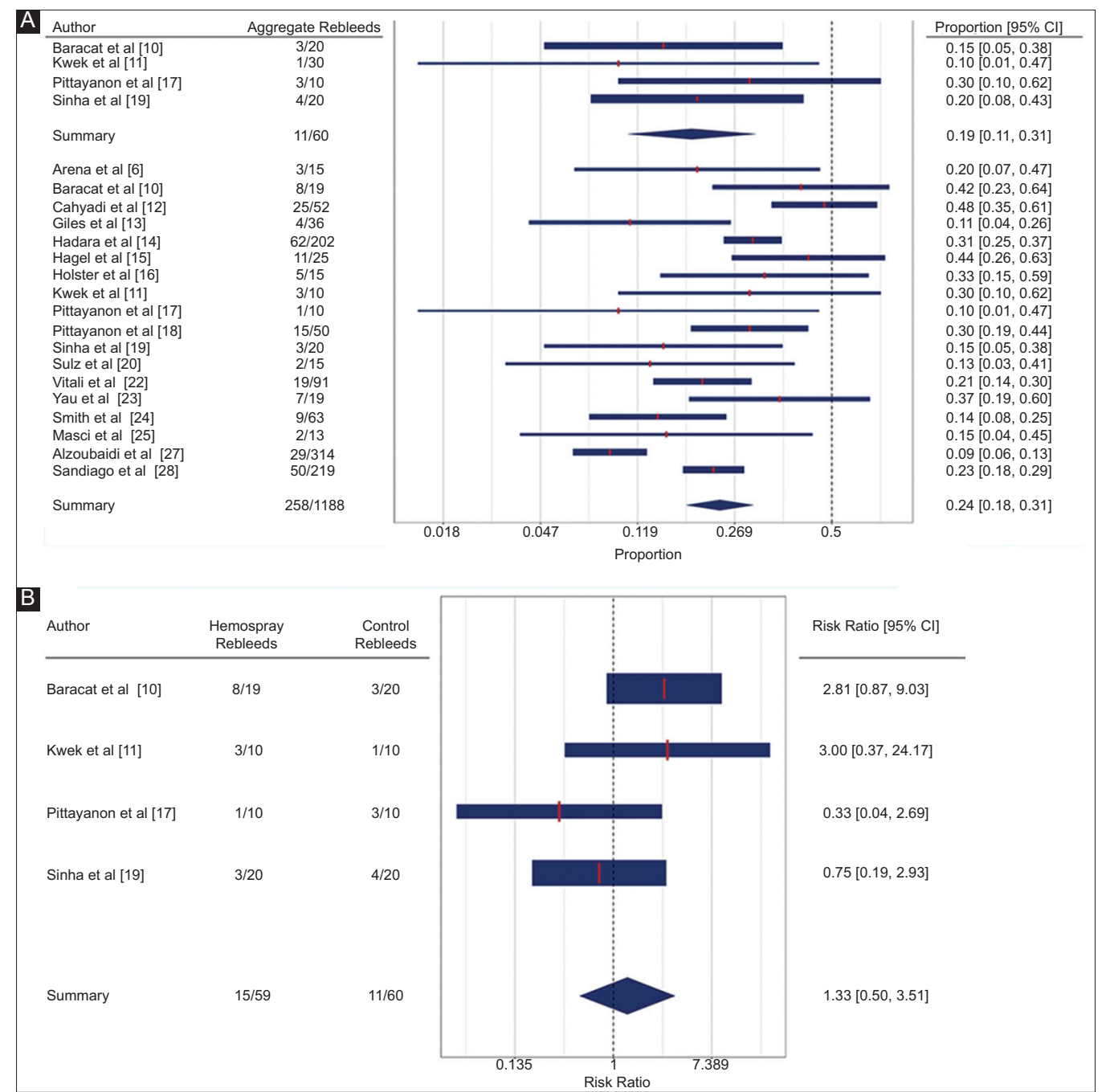

Figure 2 Forest plots with proportional (A) and risk (B) analysis for aggregate rebleeding

difference between the 2 groups (RR 1.05, 95\%CI 0.95-1.17; $\mathrm{P}=0.32, I^{2}=0.03 \%$ ) (Fig. $\left.1 \mathrm{C}\right)$.

\section{Secondary outcomes}

Two studies compared the early rebleeding rate of Hemospray to that of other hemostatic techniques and reported no significant difference between the 2 groups (RR 1.29, 95\%CI 0.02-95.32; $\mathrm{P}=0.91, I^{2}=78.29 \%$ ) (Supplementary Fig. 3B). The low sample size was not amenable to meta-regression analysis. Two studies compared the delayed rebleeding rate of Hemospray to that of other hemostatic techniques and found no significant difference between the 2 groups (RR 1.28, 95\%CI 0.34-4.83; $\mathrm{P}=0.72$, $I^{2}=0.00 \%$ ) (Supplementary Fig. 4B). Four studies compared the refractory bleeding rate of Hemospray to that of other hemostatic techniques and observed no significant difference between the 2 groups (RR 0.48, 95\%CI 0.12-1.94; $\mathrm{P}=0.30$, $I^{2}=0.00 \%$ ) (Supplementary Fig. 5B). Four studies compared the aggregate rebleeding rate of Hemospray to that of other hemostatic techniques and found no significant difference between the 2 groups (RR 1.33, 95\%CI 0.51-3.50, $\mathrm{P}=0.56$; $\left.I^{2}=32.65 \%\right)$ (Fig. 2B).

Two studies compared the failure rate of Hemospray to that of other hemostatic techniques and observed no significant difference between the 2 groups (RR 1.01, 95\%CI $0.40-2.58 ; \quad \mathrm{P}=0.98, \quad I^{2}=46.83 \%$ ) (Supplementary Fig. 6B). Three studies compared the mortality rate due to bleeding of Hemospray to that of other hemostatic techniques and reported no significant difference between the 2 groups (RR $0.66,95 \% \mathrm{CI} 0.26-1.72 ; \mathrm{P}=0.40, I^{2}=0.00 \%$ ) (Supplementary Fig. 7B).

\section{Discussion}

This systematic review and meta-analysis evaluated the efficacy of Hemospray in the management of non-variceal 
upper GIB and demonstrated a high clinical and technical success rate. The early, delayed and aggregate rebleeding rates were comparable to those in the control group. The rate of mortality due to bleeding was also low with the use of Hemospray. These results support the use of Hemospray as a viable alternative to traditional hemostatic techniques for the control of non-variceal upper GIB. The trend towards increasing technical success in the publication years from 2011-2019 may be indicative of endoscopists' familiarity with Hemospray or improvements in Hemospray production quality.

GIB continues to be a significant cause of morbidity and mortality, as well as a global healthcare burden, especially in the elderly [29]. Depending upon the location of the bleed, the size of the bleeding vessel and/or the risk of complications, endoscopists may be limited in effectively treating the source of GIB using conventional modalities [30]. In these situations, Hemospray may have an advantage in the treatment of these difficult bleeding lesions. Moreover, in the setting of significant GIB, conventional endoscopic therapies require a certain level of skill and expertise on part of the endoscopist, which may not be available [30]. Hemospray requires less technical expertise for its application, as it is a non-thermal, non-contact modality that does not require a high degree of precision. Therefore, it may have a wider applicability, especially by physicians trained in endoscopy but are not necessarily experts in managing GIB [30]. This may be of particular importance in remote areas where access to skilled endoscopists is limited [31].

A major cause of death amongst patients admitted for GIB is refractory bleeding, or failure to achieve initial hemostasis during the endoscopic procedure. Mortality in patients with upper GIB has been reported to be as high as $30 \%$ among inpatients, predominantly secondary to failed initial endoscopic hemostasis [32]. The utility of Hemospray as a hemostatic agent is evident in the high rates of initial hemostasis and low rates of refractory bleeding. Our study showed that refractory bleeding following the use of Hemospray occurred in only $8 \%$ of patients, compared to $13 \%$ of patients in the control group. Hence, Hemospray may be an attractive and effective option to reduce refractory bleeding rates. Additionally, in exsanguinating bleeding lesions not effectively controlled by conventional therapies, Hemospray may serve as a temporizing second-line agent and a bridge to subsequent definitive hemostasis, thereby limiting refractory bleeding.

An important aspect of novel therapeutic modalities is the economic burden contingent on the at-risk population. From a financial perspective, Hemospray has proven to be a cost-effective therapy. In a large study examining a US national inpatient population, Hemospray was shown to be less expensive than all other approaches [33]. Furthermore, the second most cost-effective approach was \$635 USD more expensive per patient than Hemospray [33]. However, the hemostatic time of Hemospray may be called into question. Two studies have attempted second-look endoscopy post-Hemospray application for non-variceal bleeds $[12,34]$. Cahyadi et al noted that $36.5 \%$ of patients treated with Hemospray receiving second-look endoscopy had rebleeding at the time of endoscopy; $68.4 \%$ of these patients received a second application of Hemospray, which adequately provided hemostasis [12]. Likewise, Chen et al performed second-look endoscopy on $43 \%$ of patients treated with Hemospray, $33 \%$ of whom had rebleeding; all received secondary therapies including Hemospray, electrocautery and hemoclips with epinephrine injection [34].

The main limitation of this meta-analysis is that only 2 RCTs were available. To partially circumvent this limitation, we included both randomized and non-randomized trials in the proportional meta-analysis and ratio-based metaanalysis. However, the inclusion of studies with a nonrandomized design introduces possible significant selection bias. Secondly, the total number of patients in the RR metaanalysis was relatively low. In addition, given the scarcity of data, we could not identify the impact of Hemospray as monotherapy, in combination with other agents, or as a rescue agent. However, in most cases Hemospray was the final hemostatic agent used in combination therapy and the sole or final hemostatic agent used in rescue therapy, implying hemostatic success specifically related to Hemospray. Another limitation was the inconsistent identification of bleeding sources in the analyzed papers, as well as specific hemostatic modalities in certain studies. Lastly, endoscopist expertise and self-reporting data are subjective and the possibility of non-random user error remains. These limitations are partially attenuated by the combined statistical power of a large number of studies with a vast and diverse study population included in the proportional meta-analysis, which gives a general idea of the overall success and failure rates. Additionally, we set forth strict inclusion and exclusion criteria to limit bias and included only those studies that involved patients with non-variceal upper GIB.

The results herein indicate that Hemospray is non-inferior to conventional hemostatic modalities for the efficacious termination of non-variceal upper GIB. Hemospray can potentially be used as an alternative option for the management of non-variceal upper GIB. Given its ease of use, in tandem with the reduced technical expertise needed for deployment relative to other modalities, Hemospray has the potential to become an attractive therapy for the management of upper GIB. Future research, including RCTs and large cohort studies, are needed to specifically compare Hemospray to other hemostatic powders, as well as to other individual, mechanical modalities. These data will help in the development of appropriate recommendations regarding the use of Hemospray, as well as its position in the GIB algorithm. Additionally, for the future, larger studies are needed to more accurately comment on the efficacy of Hemospray in upper variceal hemorrhage and lower bleeds, in an attempt to widen its scope of application to all GIB. 


\section{Summary Box}

\section{What is already known:}

- Conventional methods of hemostasis for nonvariceal upper gastrointestinal bleeding (GIB) include injectable, thermal and mechanical therapies

- Hemospray (TC-325), developed by Cook Medical, has been evaluated for its safety and efficacy in numerous studies

- The safety and efficacy of Hemospray have been demonstrated in small retrospective and prospective cohort studies as well as small randomized controlled trials (RCTs)

\section{What the new findings are:}

- Our meta-analysis showed high technical (97\%) and clinical (91\%) success for Hemospray in controlling upper GIB

- The comparative meta-analysis (4 studies) did not demonstrate any significant difference between Hemospray and conventional hemostatic techniques in terms of clinical success, early or delayed rebleeding, and all-cause mortality

- Given the high clinical and technical success rates, outcomes comparable to conventional hemostatic measure and the relative ease of use, Hemospray can be considered as an alternative to first-line endoscopic measures to achieve hemostasis in non-variceal upper GIB

\section{References}

1. El-Tawil AM. Trends on gastrointestinal bleeding and mortality: where are we standing? World J Gastroenterol 2012;18:1154-1158.

2. Changela K, Papafragkakis H, Ofori E, et al. Hemostatic powder spray: a new method for managing gastrointestinal bleeding. Therap Adv Gastroenterol 2015;8:125-135.

3. Mourad FH, Leong RW. Role of hemostatic powders in the management of lower gastrointestinal bleeding: A review. J Gastroenterol Hepatol 2018;33:1445-1453.

4. Barkun AN, Moosavi S, Martel M. Topical hemostatic agents: a systematic review with particular emphasis on endoscopic application in GI bleeding. Gastrointest Endosc 2013;77:692-700.

5. Szura M, Pasternak A. Upper non-variceal gastrointestinal bleeding - review the effectiveness of endoscopic hemostasis methods. World J Gastrointest Endosc 2015;7:1088-1095.

6. Arena M, Masci E, Eusebi LH, et al. Hemospray for treatment of acute bleeding due to upper gastrointestinal tumours. Dig Liver Dis 2017;49:514-517.

7. Chen YI, Barkun AN, Soulellis C, Mayrand S, Ghali P. Use of the endoscopically applied hemostatic powder TC-325 in cancerrelated upper GI hemorrhage: preliminary experience (with video). Gastrointest Endosc 2012;75:1278-1281.

8. Higgins JPT GS. Cochrane handbook for systematic reviews of interventions. In: Higgins JPT GS, editor. The Cochrane Collaboration: The Cochrane Collaboration, 2011.

9. Deeks JJ, Dinnes J, D’Amico R, et al; European Carotid Surgery Trial Collaborative Group. Evaluating non-randomised intervention studies. Health Technol Assess 2003;7:iii-x.

10. Baracat FI, de Moura DTH, Brunaldi VO, et al. Randomized controlled trial of hemostatic powder versus endoscopic clipping for non-variceal upper gastrointestinal bleeding. Surg Endosc 2019 Mar 29 [Epub ahead of print]. doi: 10.1007/s00464-01906769-z

11. Kwek BEA, Ang TL, Ong PLJ, et al. TC-325 versus the conventional combined technique for endoscopic treatment of peptic ulcers with high-risk bleeding stigmata: A randomized pilot study. J Dig Dis 2017; 18:323-329.

12. Cahyadi O, Bauder M, Meier B, Caca K, Schmidt A. Effectiveness of TC-325 (Hemospray) for treatment of diffuse or refractory upper gastrointestinal bleeding - a single center experience. Endosc Int Open 2017;5:E1159-E1164.

13. Giles H, Lal D, Gerred S, et al. Efficacy and safety of TC-325 (HemosprayTM) for non-variceal upper gastrointestinal bleeding at Middlemore Hospital: the early New Zealand experience. $N Z$ Med J 2016;129:38-43.

14. Haddara S, Jacques J, Lecleire S, et al. A novel hemostatic powder for upper gastrointestinal bleeding: a multicenter study (the “GRAPHE” registry). Endoscopy 2016;48:1084-1095.

15. Hagel AF, Albrecht H, Nägel A, et al. The application of hemospray in gastrointestinal bleeding during emergency endoscopy. Gastroenterol Res Pract 2017;2017:3083481.

16. Holster IL, Kuipers EJ, Tjwa ET. Hemospray in the treatment of upper gastrointestinal hemorrhage in patients on antithrombotic therapy. Endoscopy 2013;45:63-66.

17. Pittayanon R, Prueksapanich P, Rerknimitr R. The efficacy of Hemospray in patients with upper gastrointestinal bleeding from tumor. Endosc Int Open 2016;4:E933-E936.

18. Pittayanon R, Rerknimitr R, Barkun A. Prognostic factors affecting outcomes in patients with malignant GI bleeding treated with a novel endoscopically delivered hemostatic powder. Gastrointest Endosc 2018;87:994-1002.

19. Sinha R, Lockman KA, Church NI, Plevris JN, Hayes PC. The use of hemostatic spray as an adjunct to conventional hemostatic measures in high-risk nonvariceal upper GI bleeding (with video). Gastrointest Endosc 2016;84:900-906.

20. Sulz MC, Frei R, Meyenberger C, Bauerfeind P, Semadeni GM, Gubler C. Routine use of Hemospray for gastrointestinal bleeding: prospective two-center experience in Switzerland. Endoscopy 2014;46:619-624.

21. Sung JJ, Luo D, Wu JC, et al. Early clinical experience of the safety and effectiveness of Hemospray in achieving hemostasis in patients with acute peptic ulcer bleeding. Endoscopy 2011;43:291-295.

22. Vitali F, Naegel A, Atreya R, et al. Comparison of Hemospray ${ }^{\circledR}$ and Endoclot $^{\mathrm{TM}}$ for the treatment of gastrointestinal bleeding. World $J$ Gastroenterol 2019;25:1592-1602.

23. Yau AH, Ou G, Galorport C, et al. Safety and efficacy of Hemospray ${ }^{\circledR}$ in upper gastrointestinal bleeding. Can J Gastroenterol Hepatol 2014;28:72-76.

24. Smith LA, Stanley AJ, Bergman JJ, et al. Hemospray application in nonvariceal upper gastrointestinal bleeding: results of the Survey to Evaluate the Application of Hemospray in the Luminal Tract. J Clin Gastroenterol 2014;48:e89-e92.

25. Masci E, Arena M, Morandi E, Viaggi P, Mangiavillano B. Upper gastrointestinal active bleeding ulcers: review of literature on the results of endoscopic techniques and our experience with Hemospray. Scand J Gastroenterol 2014;49:1290-1295.

26. Leblanc S, Vienne A, Dhooge M, Coriat R, Chaussade S, Prat F. Early experience with a novel hemostatic powder used to treat 
upper GI bleeding related to malignancies or after therapeutic interventions (with videos). Gastrointest Endosc 2013;78:169-175.

27. Alzoubaidi D, Hussein M, Rusu R, et al. Outcomes from an international multicenter registry of patients with acute gastrointestinal bleeding undergoing endoscopic treatment with Hemospray. Dig Endosc 2019 Jul 31 [Epub ahead of print]. doi: 10.1111/den.13502.

28. Rodríguez de Santiago E, Burgos-Santamaría D, Pérez-Carazo L, et al; TC-325 Collaboration Project, Endoscopy Group of the Spanish Association of Gastroenterology. Hemostatic spray powder TC-325 for GI bleeding in a nationwide study: survival and predictors of failure via competing risks analysis. Gastrointest Endosc 2019;90:581-590.

29. Yavorski RT, Wong RK, Maydonovitch C, Battin LS, Furnia A, Amundson DE. Analysis of 3,294 cases of upper gastrointestinal bleeding in military medical facilities. Am J Gastroenterol 1995;90:568-573.
30. Saltzman JR. Hemostatic spray for the management of gastrointestinal bleeding. Gastroenterol Hepatol (N Y) 2019; 15:40-43.

31. Rosenblatt RA, Hart LG. Physicians and rural America. West J Med 2000;173:348-351.

32. Hearnshaw SA, Logan RF, Lowe D, Travis SP, Murphy MF, Palmer KR. Acute upper gastrointestinal bleeding in the UK: patient characteristics, diagnoses and outcomes in the 2007 UK audit. Gut 2011;60:1327-1335.

33. Barkun AN, Adam V, Lu Y, Chen YI, Martel M. Using Hemospray improves the cost-effectiveness ratio in the management of upper gastrointestinal nonvariceal bleeding. J Clin Gastroenterol 2018;52:36-44.

34. Chen YI, Barkun A, Nolan S. Hemostatic powder TC-325 in the management of upper and lower gastrointestinal bleeding: a twoyear experience at a single institution. Endoscopy 2015;47:167-171. 


\section{Supplementary}

Supplementary Table 1 Search strategy using PubMed

\begin{tabular}{|c|c|c|}
\hline Search & Query & Items found \\
\hline$\# 1$ & (“Gastrointestinal Hemorrhage”[Mesh]) AND “Hemorrhage”[Mesh]) & 49266 \\
\hline$\# 2$ & ((“Hemospray” OR “TC-325”)) & 96 \\
\hline \#3 & $\# 1$ and $\# 2$ & 59 \\
\hline \#4 & $\begin{array}{l}\text { \# } 3 \text { NOT (“"case reports"[Publication Type] OR "editorial”[Publication Type] OR "guideline”[Publication Type] OR } \\
\text { "introductory journal article"[Publication Type] OR "meta-analysis"[Publication Type] OR "news"[Publication Type] } \\
\text { OR "practice guideline"[Publication Type] OR "review"[Publication Type] OR "systematic review"[Publication Type])) }\end{array}$ & 35 \\
\hline \#5 & 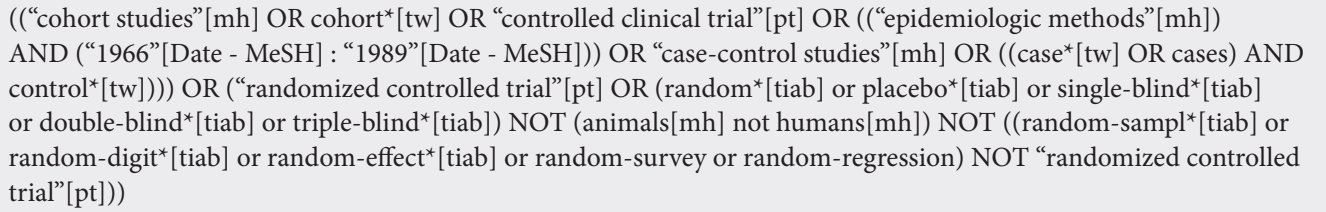 & 3807520 \\
\hline \# 6 & $\# 4$ and $\# 5$ & 13 \\
\hline
\end{tabular}

Supplementary Table 2 Risk of bias in the randomized controlled trials

\begin{tabular}{lllllll}
\hline Study & $\begin{array}{l}\text { Random sequence } \\
\text { generation } \\
\text { (selection bias) }\end{array}$ & $\begin{array}{l}\text { Allocation } \\
\text { concealment } \\
\text { (selection bias) }\end{array}$ & $\begin{array}{l}\text { Blinding of participants } \\
\text { and personnel } \\
\text { (performance bias) }\end{array}$ & $\begin{array}{l}\text { Blinding of } \\
\text { outcome assessment } \\
\text { (detection bias) }\end{array}$ & $\begin{array}{l}\text { Incomplete } \\
\text { outcome data } \\
\text { (attrition bias) }\end{array}$ & $\begin{array}{l}\text { Selective } \\
\text { reporting } \\
\text { (reporting bias) }\end{array}$ \\
\hline $\begin{array}{l}\text { Baracat } \\
\text { et al }[10]\end{array}$ & Low & Low & High & Unknown & Low & Low \\
$\begin{array}{l}\text { Kwek } \\
\text { et al }[1]]\end{array}$ & Low & Unknown & High & Unknown & Low & Low \\
\hline
\end{tabular}




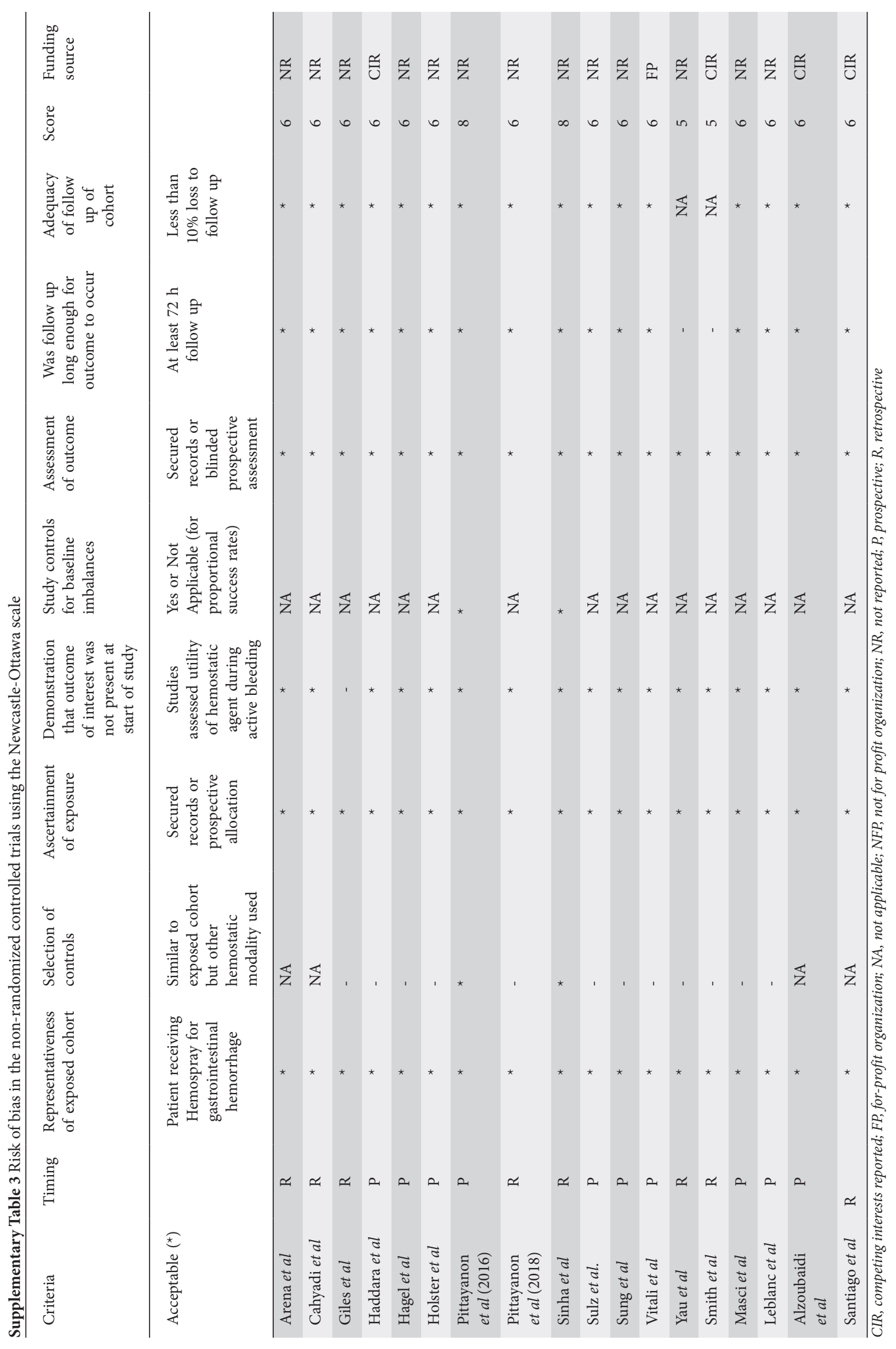


Supplementary Table 4 Primary outcomes

Primary outcomes

\begin{tabular}{|c|c|c|c|c|c|}
\hline Proportional analysis & Proportion & CI lower (P) & CI upper $(\mathrm{P})$ & P-value & $I^{2}$ \\
\hline Technical success & 0.97 & 0.94 & 0.98 & $<0.0001$ & 52.89 \\
\hline Clinical success (control) & 0.87 & 0.75 & 0.94 & $<0.0001$ & 0.00 \\
\hline $\begin{array}{l}\text { Clinical } \\
\text { success (intervention) }\end{array}$ & 0.91 & 0.88 & 0.94 & $<0.0001$ & 52.89 \\
\hline Comparative Analysis & Risk Ratio & CI lower (RR) & CI upper (RR) & P-value & $I^{2}$ \\
\hline Clinical success & 1.05 & 0.95 & 1.17 & 0.32 & 0.03 \\
\hline
\end{tabular}

$C I$, confidence interval; $R R$, relative risk

Supplementary Table 5 Secondary outcomes

\begin{tabular}{|c|c|c|c|c|c|}
\hline Proportional Analysis & Proportion & CI lower (P) & CI upper $(\mathrm{P})$ & P-value & $I^{2}$ \\
\hline Aggregate rebleed rate (control) & 0.19 & 0.11 & 0.31 & $<0.001$ & 0.00 \\
\hline Aggregate rebleed rate (intervention) & 0.24 & 0.18 & 0.31 & $<0.001$ & 77.57 \\
\hline Early rebleed rate (control) & 0.12 & 0.01 & 0.68 & 0.15 & 69.27 \\
\hline Early rebleed rate (intervention) & 0.20 & 0.14 & 0.29 & $<0.001$ & 56.73 \\
\hline Delayed rebleed rate (control) & 0.13 & 0.04 & 0.31 & $<0.001$ & 0.00 \\
\hline Delayed rebleed rate (intervention) & 0.09 & 0.06 & 0.12 & $<0.001$ & 0.00 \\
\hline Refractory rebleed rate (control) & 0.13 & 0.06 & 0.25 & $<0.001$ & 0.00 \\
\hline Refractory rebleed rate (intervention) & 0.08 & 0.06 & 0.11 & $<0.001$ & 41.16 \\
\hline Treatment failure (control) & 0.30 & 0.19 & 0.43 & $<0.001$ & 0.00 \\
\hline Treatment failure (intervention) & 0.31 & 0.26 & 0.37 & $<0.001$ & 66.05 \\
\hline Mortality (control) & 0.21 & 0.11 & 0.34 & $<0.001$ & 0.00 \\
\hline Mortality (intervention) & 0.08 & 0.05 & 0.13 & $<0.001$ & 32.54 \\
\hline Relative Risk Analysis & Risk Ratio & CI lower (RR) & CI upper (RR) & $\mathrm{P}$-value & $I^{2}$ \\
\hline Aggregate rebleed rate & 1.33 & 0.51 & 3.50 & 0.56 & 32.65 \\
\hline Early rebleed rate & 1.29 & 0.02 & 95.32 & 0.91 & 78.29 \\
\hline Delayed rebleed rate & 1.28 & 0.34 & 4.83 & 0.72 & 0.00 \\
\hline Refractory bleeding rate & 0.48 & 0.12 & 1.94 & 0.30 & 0.00 \\
\hline Treatment failure & 0.79 & 0.05 & 13.19 & 0.87 & 68.18 \\
\hline Mortality rate & 0.66 & 0.26 & 1.72 & 0.40 & 0.00 \\
\hline
\end{tabular}

CI, confidence interval 


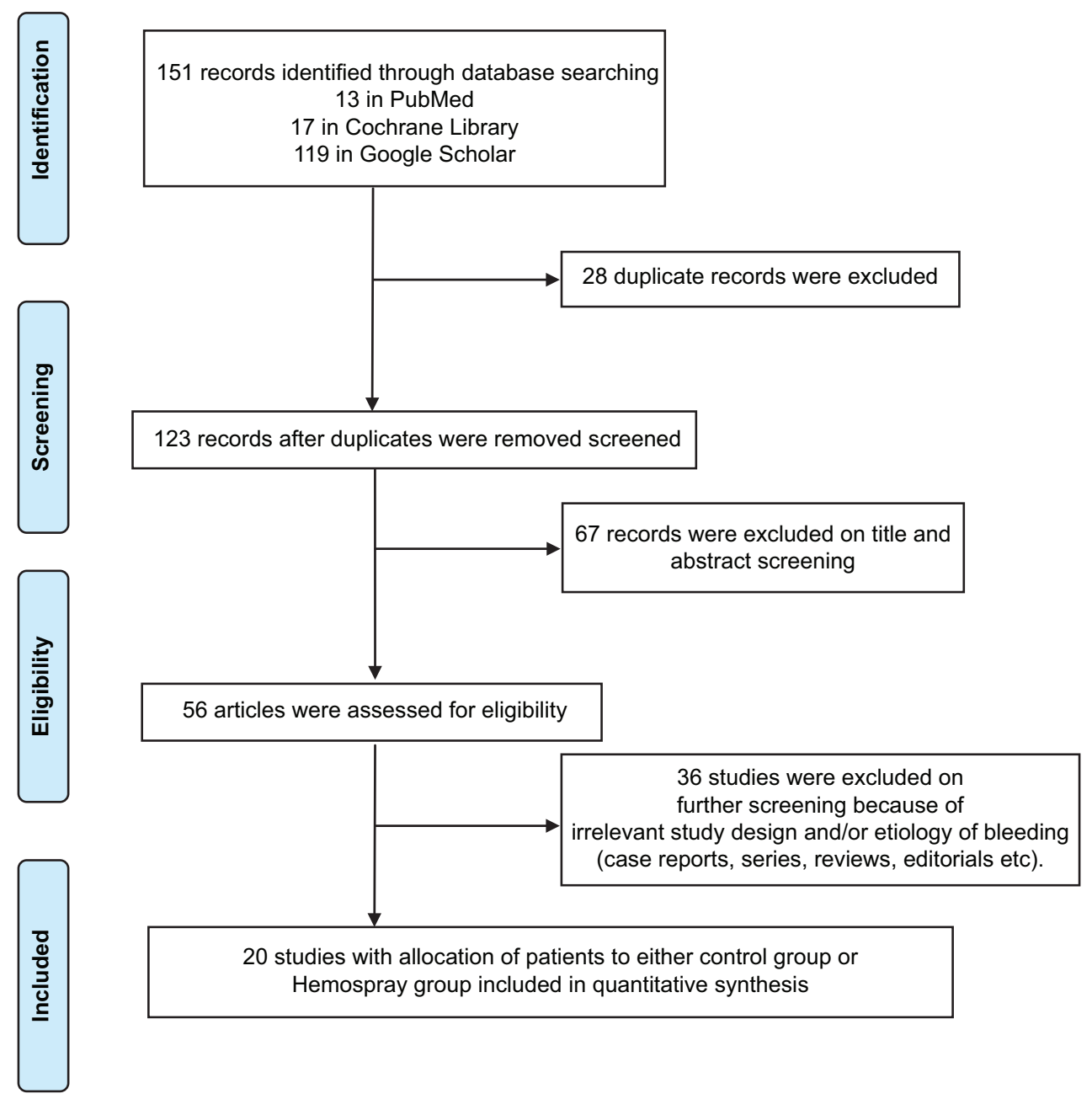

Supplementary Figure 1 Flow diagram representing the selection of studies

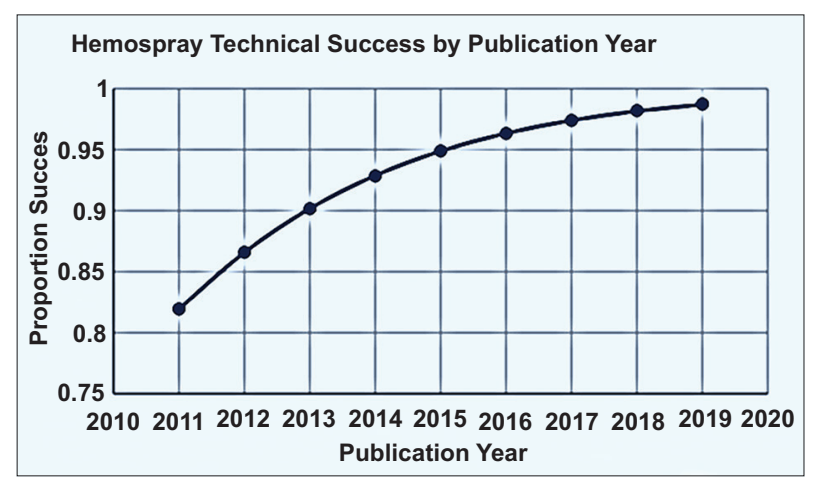

Supplementary Figure 2 Proportional success of Hemospray by publication year 


\section{A}

\begin{tabular}{lc} 
Author & Early Rebleed Rate \\
\hline Baracat et al [10] & $0 / 20$ \\
Pittayanon et al [17] & $3 / 10$ \\
Summary & $3 / 30$ \\
& \\
Arena et al [6] & $2 / 15$ \\
Baracat et al [10] & $5 / 19$ \\
Cahyadi et al [12] & $22 / 52$ \\
Holster et al [16] & $4 / 15$ \\
Pittayanon et al [17] & $0 / 10$ \\
Pittayanon et al [18] & $8 / 50$ \\
Sulz et al [20] & $2 / 15$ \\
Sung et al [21] & $3 / 20$ \\
Masci et al [25] & $2 / 13$ \\
Sandiago et al [28] & $35 / 219$ \\
& \\
Summary & $83 / 428$
\end{tabular}

B

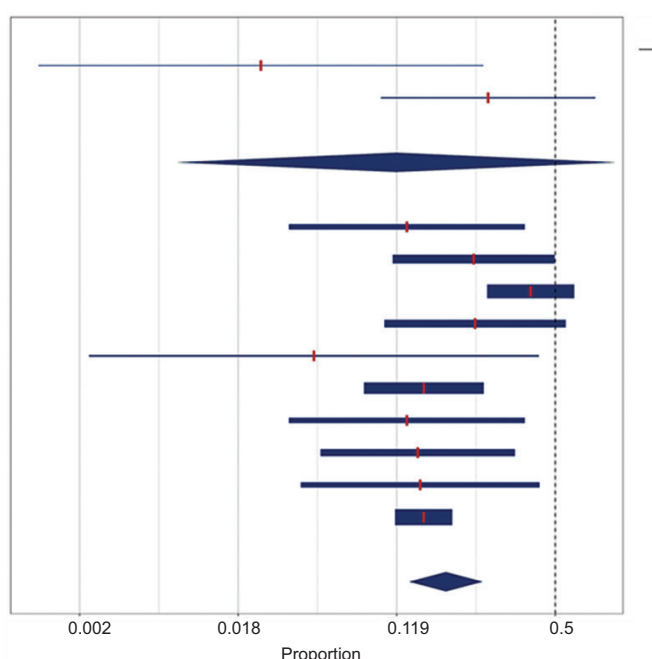

Proportion $[95 \% \mathrm{Cl}]$ $0.02[0.00,0.29]$

$0.30[0.10,0.62]$

$0.12[0.01,0.68]$

$0.13[0.03,0.41]$

$0.26[0.11,0.50]$

$0.42[0.30,0.56]$

$0.27[0.10,0.53]$

$0.05[0.00,0.45]$

$0.16[0.08,0.29]$

$0.13[0.03,0.41]$

$0.15[0.05,0.38]$

$0.15[0.04,0.45]$

$0.16[0.12,0.21]$

$0.20[0.14,0.29]$

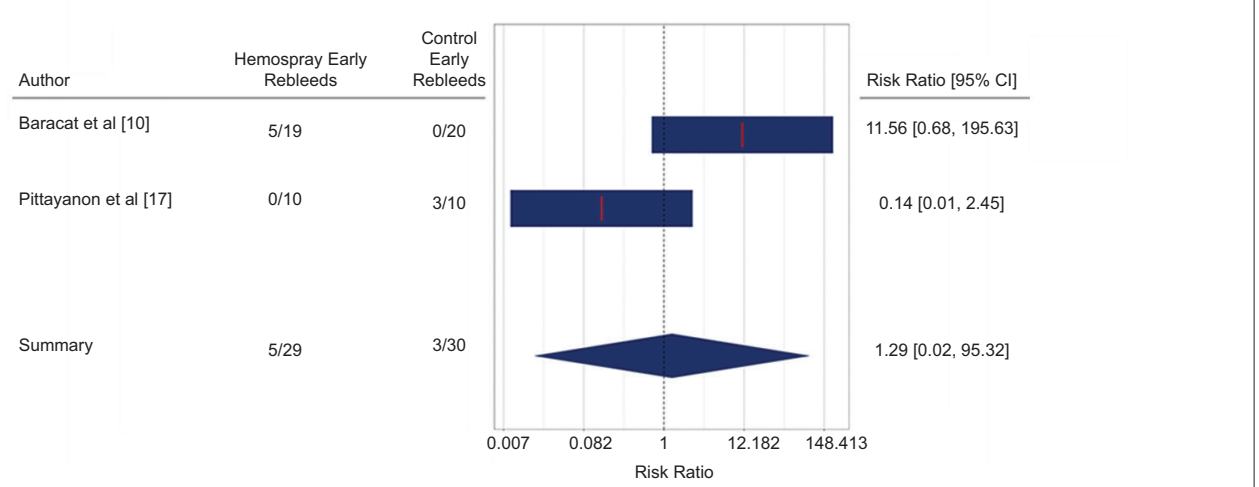

Supplementary Figure 3 Forest plots with proportional (A) and risk (B) analysis for early rebleeding 


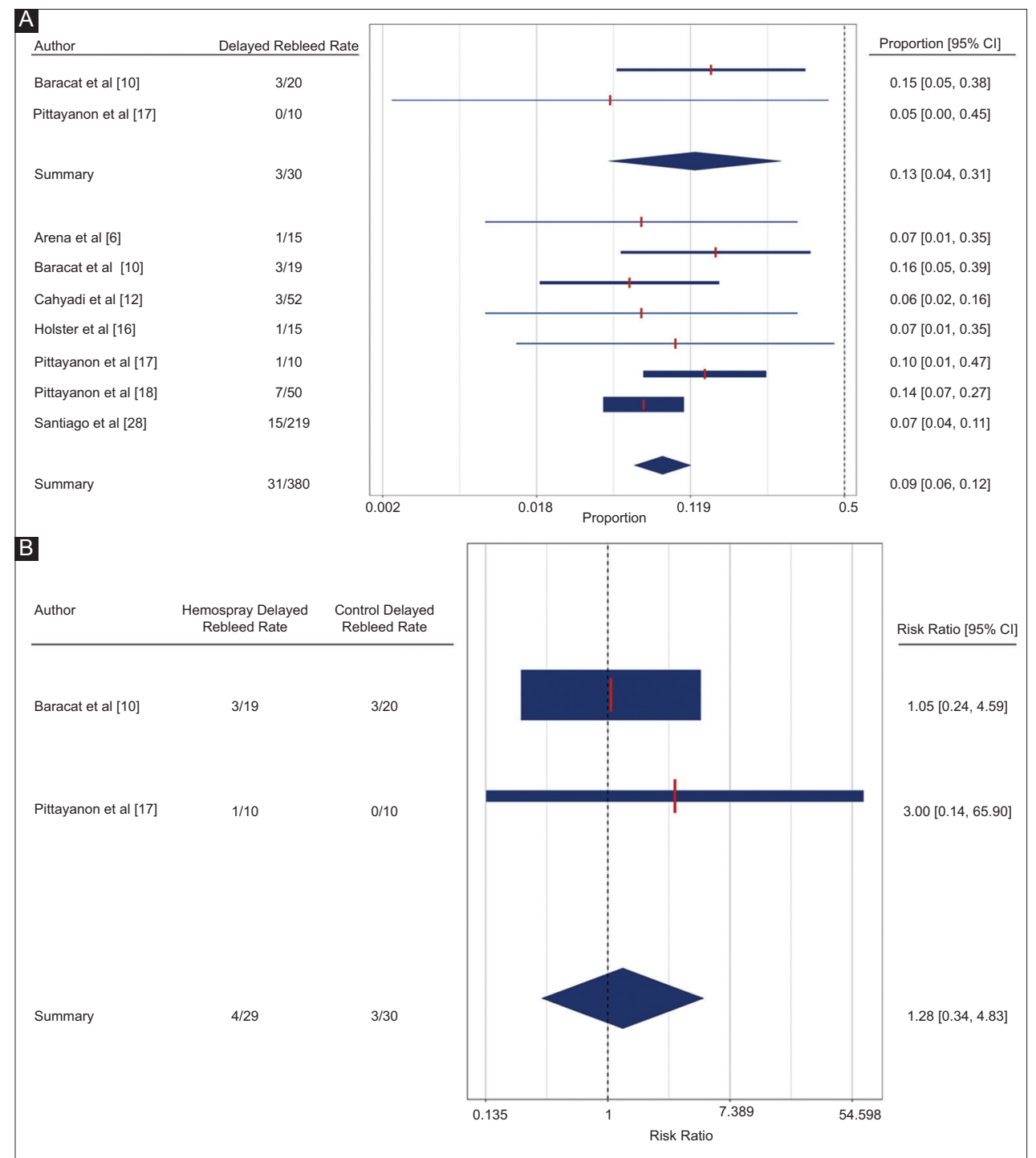

Supplementary Figure 4 Forest plots with proportional (A) and risk (B) analysis for delayed rebleeding 


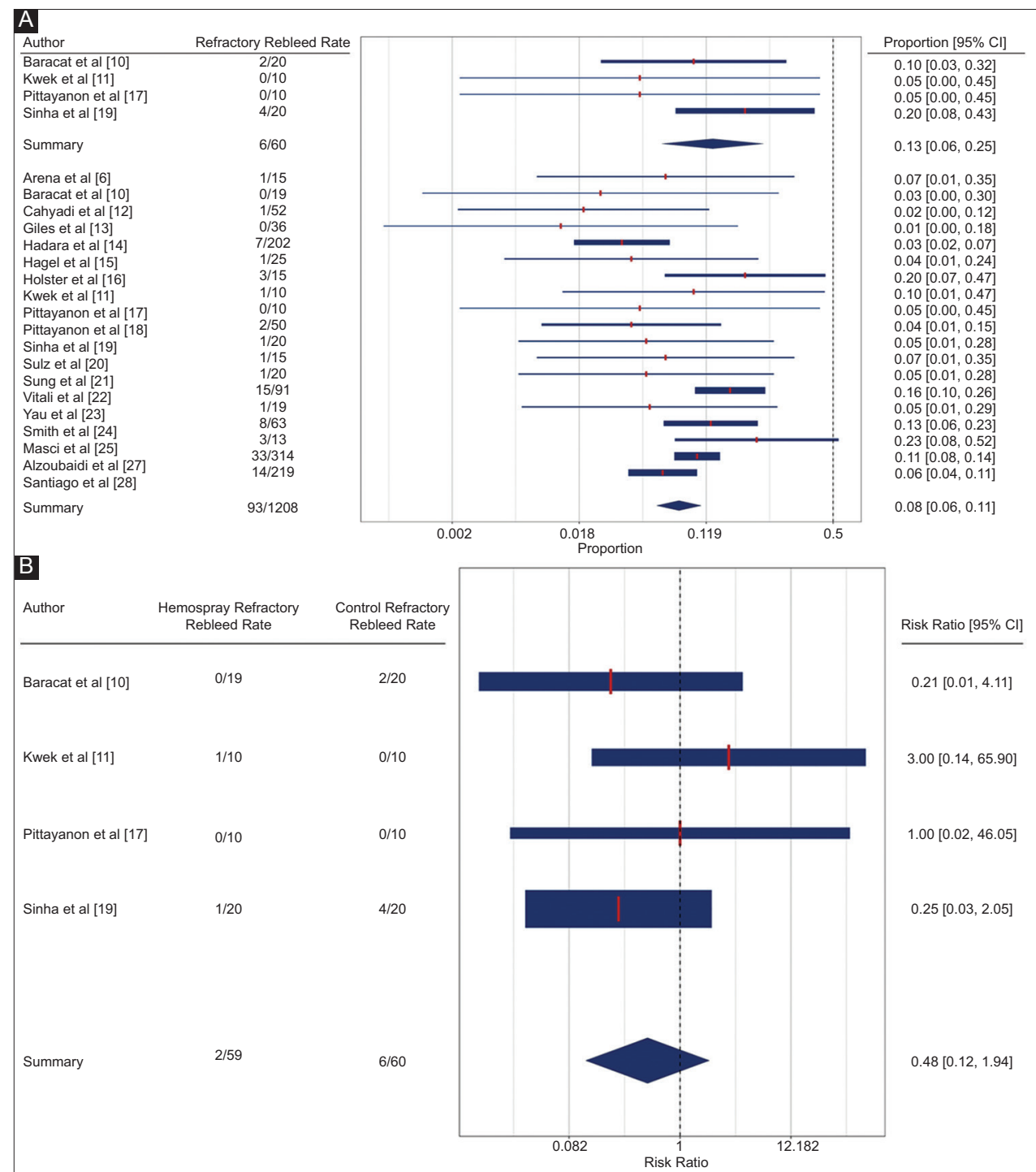

Supplementary Figure 5 Forest plots with proportional (A) and risk (B) analysis for refractory rebleeding 


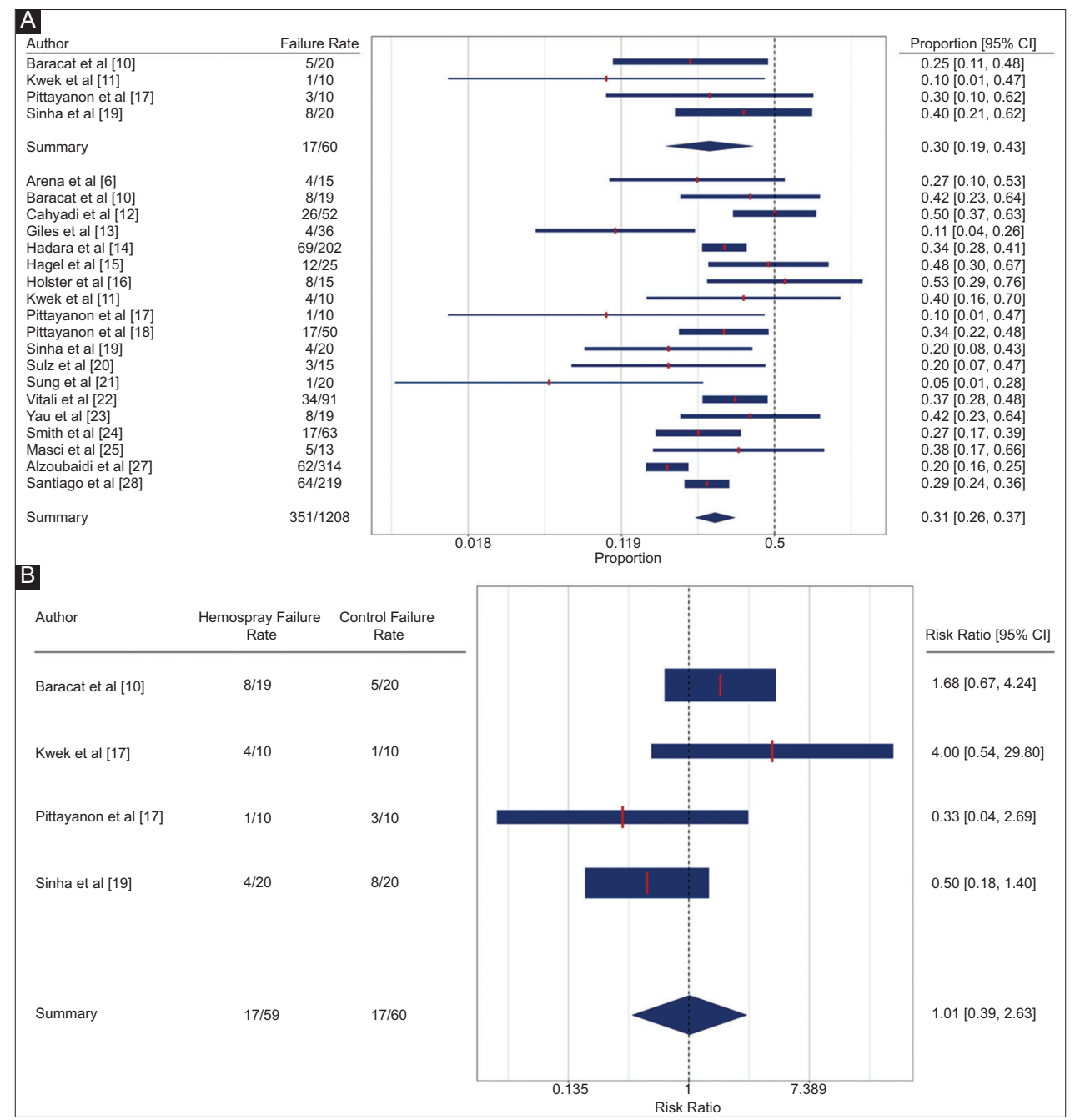

Supplementary Figure 6 Forest plots with proportional (A) and risk (B) analysis for treatment failure 


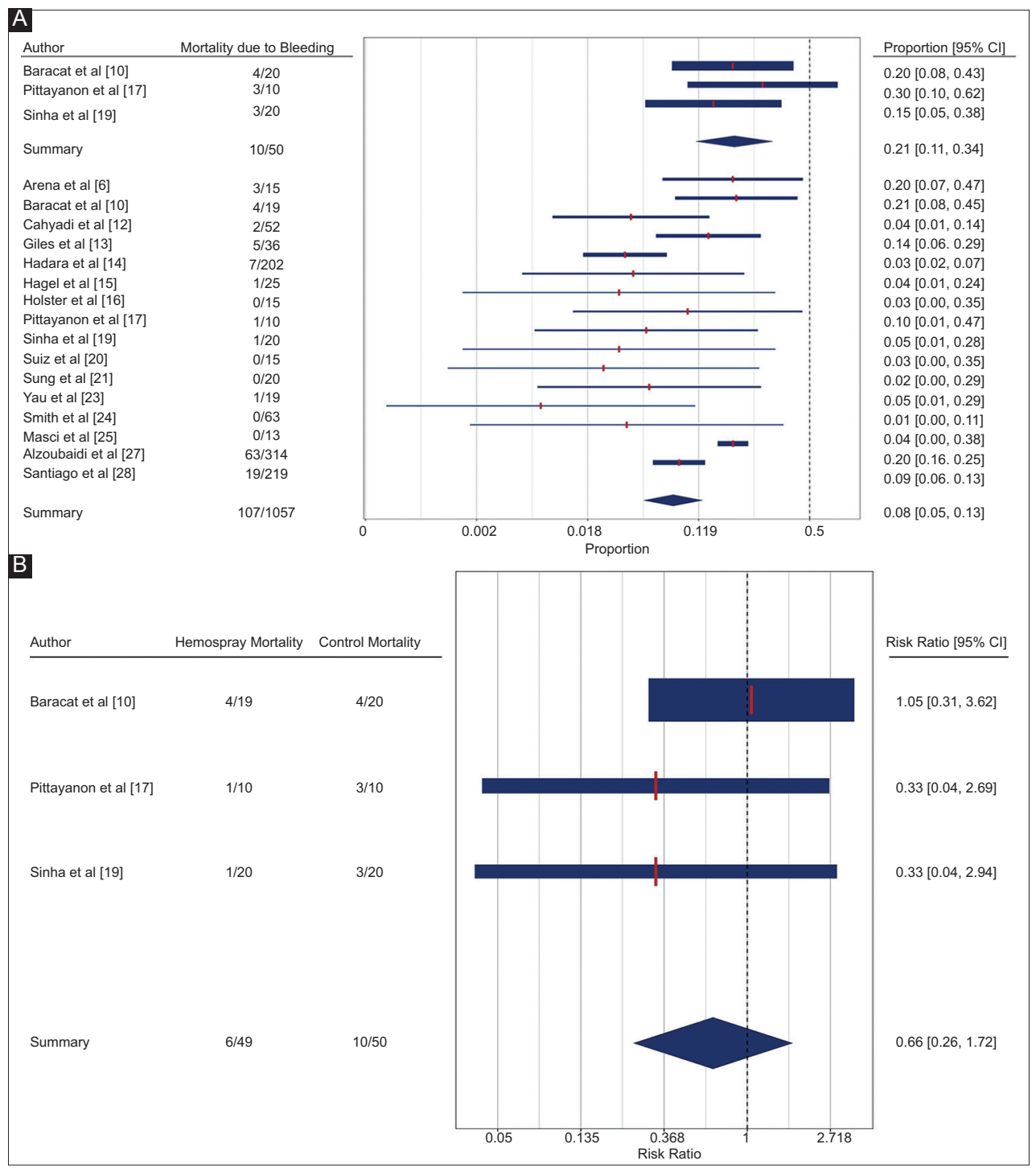

Supplementary Figure 7 Forest plots with proportional (A) and risk (B) analysis for mortality 